\title{
Antigenic Changes in Lipopolysaccharide I of Rhizobium leguminosarum bv. viciae in Root Nodules of Vicia sativa subsp. nigra Occur during Release from Infection Threads
}

\author{
LEENTJE GOOSEN-DE ROO,* RUUD A. DE MAAGD, AND BEN J. J. LUGTENBERG \\ Department of Plant Molecular Biology, Botanical Laboratory, Leiden University, \\ Nonnensteeg 3, 2311 VJ Leiden, The Netherlands
}

Received 29 October 1990/Accepted 7 March 1991

\begin{abstract}
Three different monoclonal antibodies raised against the $\mathrm{O}$ antigen-containing lipopolysaccharide (LPS I) of free-living cells were used in an immunocytochemical study to follow the fate of LPS I on the outer membrane of Rhizobium leguminosarum bv. viciae 248 during the nodulation of Vicia sativa subsp. nigra. After immunogold labeling, the LPS I epitopes were detected on the outer membrane of bacteria present in infection threads throughout the nodule. Epitopes were not detectable on bacteria released from the infection thread. The data show that the LPS I epitopes present on rhizobia in infection droplets disappear shortly before or during endocytosis of the bacteria into the host plant cell cytoplasm. The abruptness of the change suggests an active degradation or modification of LPS I epitopes rather than only a repression of their synthesis.
\end{abstract}

Members of the soil bacterium genus Rhizobium are capable of fixing atmospheric nitrogen when living in symbiosis with a leguminous plant. The bacteria enter the plant root through a tip-growing structure of plant origin called the infection thread. They multiply in the infection thread and reach the young nodule cells, which are meanwhile proliferating. From an infection droplet (14) at the tip of the infection thread, the bacteria enter the host plant cells through endocytosis. From then on, the bacteria are surrounded by a membrane of plant origin. The bacteria divide several times and then change in morphology by increasing in size and surface area. The resulting fully developed rhizobia, which are then called bacteroids, are capable of fixing nitrogen (10).

Some attention has been paid to changes in the outer membrane, especially to the lipopolysaccharide (LPS) part, of rhizobia during the differentiation from bacterium to bacteroid. In Rhizobium leguminosarum strains, two LPS species are distinguished by sodium dodecyl sulfate-polyacrylamide gel electrophoresis: (i) a fast-migrating band, with very similar electrophoretic mobilities in all strains, called LPS II, which probably consists of an LPS species with only a core oligosaccharide substitution on its lipid A, and (ii) the more slowly migrating LPS I, which additionally has the often heterogeneous $\mathrm{O}$ antigen, which varies in chemical composition from strain to strain $(5,8)$.

Mutants of $\boldsymbol{R}$. leguminosarum biovar viciae which lack the LPS I species induce non-nitrogen fixing nodules on Vicia sativa and Vicia hirsuta $(7,12)$. Studies indicate that LPS I plays a role both in bacterial release from the infection thread (7) and in early senescence of the bacteroids (12).

While LPS I appears to play an essential role in one or more of the stages of infection and nodulation, its amount and composition seem to change during these processes. Van Brussel et al. (16) found the cell envelopes of bacteroids to contain less LPS than do cell envelopes of free-living bacteria of $R$. leguminosarum bv. viciae. Brewin et al. (4) showed for $R$. leguminosarum bv. viciae that bacteroids

\footnotetext{
* Corresponding author.
}

contained predominantly the fast-migrating LPS, whereas the free-living bacteria contained both fast- and slow-migrating LPS species. De Maagd et al. (6) confirmed that less LPS was produced by bacteroids than by free-living bacteria. Moreover, the bacteroid LPS was less reactive with three monoclonal antibodies (MAbs) against the LPS I species of free-living bacteria. These results indicate that LPS of $R$. leguminosarum bv. viciae changes during the transition from free-living bacterium to bacteroid, resulting in a decreased presence of the LPS I species and its associated epitopes.

These findings raise the question in which stage of the symbiosis the change of LPS I actually takes place. In the present study, we used immunoelectron microscopy to follow the fate of LPS I epitopes produced by $R$. leguminosarum bv. viciae 248 in nodules of $V$. sativa subsp. nigra. In order to determine the stage at which the LPS I epitopes decrease or disappear, three different MAbs interacting with LPS I $(6,7)$ were used to localize LPS I epitopes at the outer membrane of bacteria both in infection threads as well as after release from the threads during differentiation into bacteroids. The results show that the LPS I-specific epitopes disappear at the onset of endocytosis, probably in the infection droplet. The abruptness of the disappearance indicates an active degradation or modification of the epitopes.

\section{MATERIALS AND METHODS}

Growth of bacteria and plants. Seeds of $V$. sativa $\mathrm{L}$. subsp. nigra (L.) were surface sterilized and allowed to germinate on Jensen agar plates. Seedlings with roots approximately 1 $\mathrm{cm}$ in length were used for inoculation. $R$. leguminosarum biovar viciae 248 was grown for 5 days on $\mathrm{B}^{-}$(16) agar plates. The seedlings were put onto a bacterial colony for inoculation and placed onto Jensen agar slants in test tubes (17). The inoculated seedlings grew for 3 to 4 weeks before root nodules were harvested and processed for electron microscopy.

Electron microscopy. Red nodules were harvested from the seedling roots and fixed overnight at room temperature in $1 \%$ glutaraldehyde- $2 \%$ paraformaldehyde- $0.1 \mathrm{M}$ sodium cacodylate buffer, $\mathrm{pH}$ 7.2. The nodules were washed in the same 

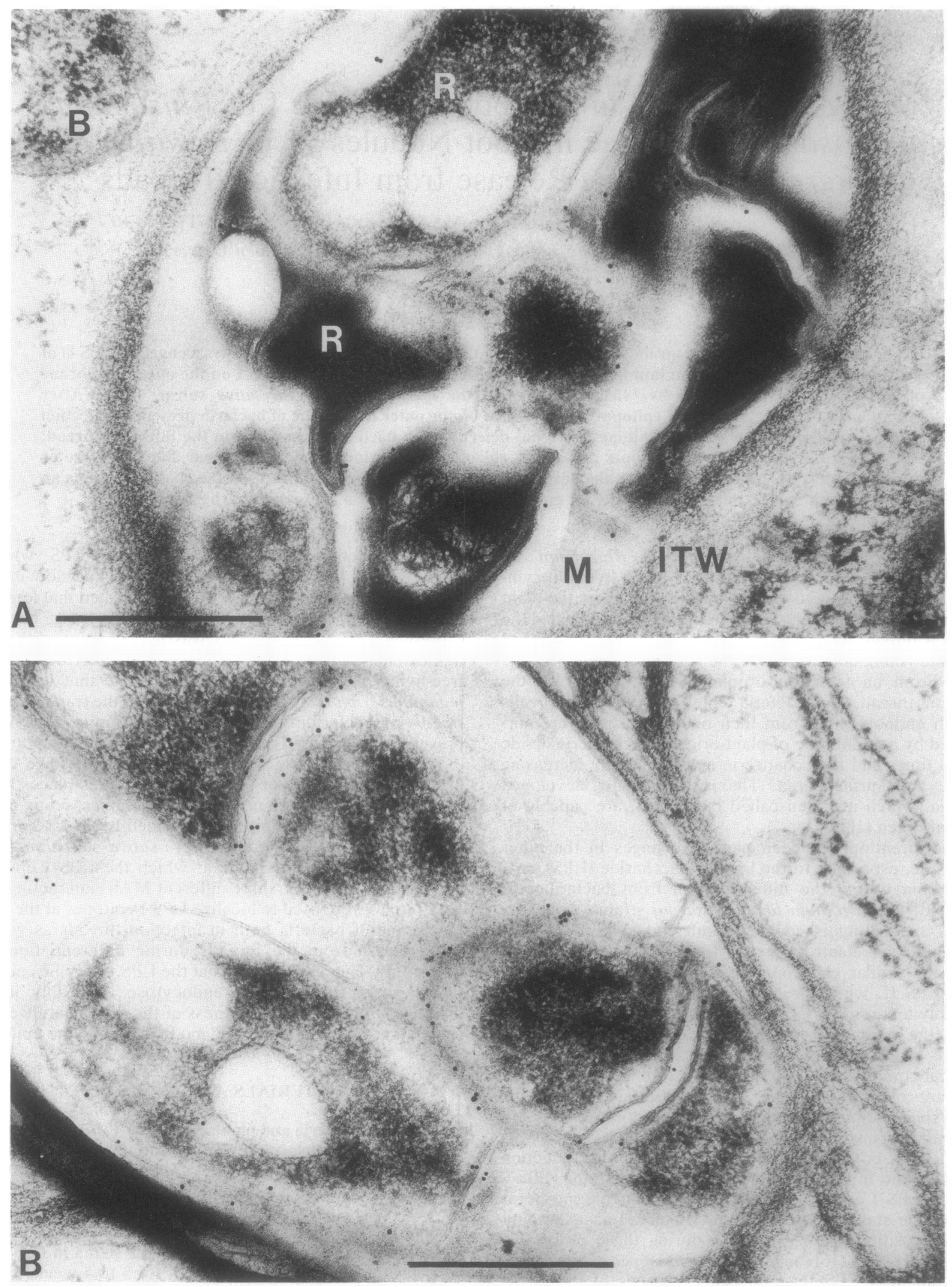

FIG. 1. R. leguminosarum bv. viciae bacteria in infection threads in root nodules of Vicia sativa subsp. nigra. (A) Obliquely and (in part) transversely sectioned infection thread with closely packed, irregularly shaped rhizobia (R), some of which contain poly- $\beta$-hydroxybutyrate granules. Around some bacteria, an electron-translucent area is present. In the infection thread, matrix material (N.) is present which is bordered by the fibrillar infection thread cell wall (ITW). After immunolabeling with MAb 24, gold particles are found on the outer membrane of the rhizobia but not on the bacteroid (B) in the cytoplasm of the host cell. Bar, $0.5 \mu \mathrm{m}$. (B) Bacteria in infection thread, immunolabeled with MAb 16. The outer membrane of the bacteria is labeled more intensely than it is with MAb 24 . Bar, $0.5 \mu \mathrm{m}$. 

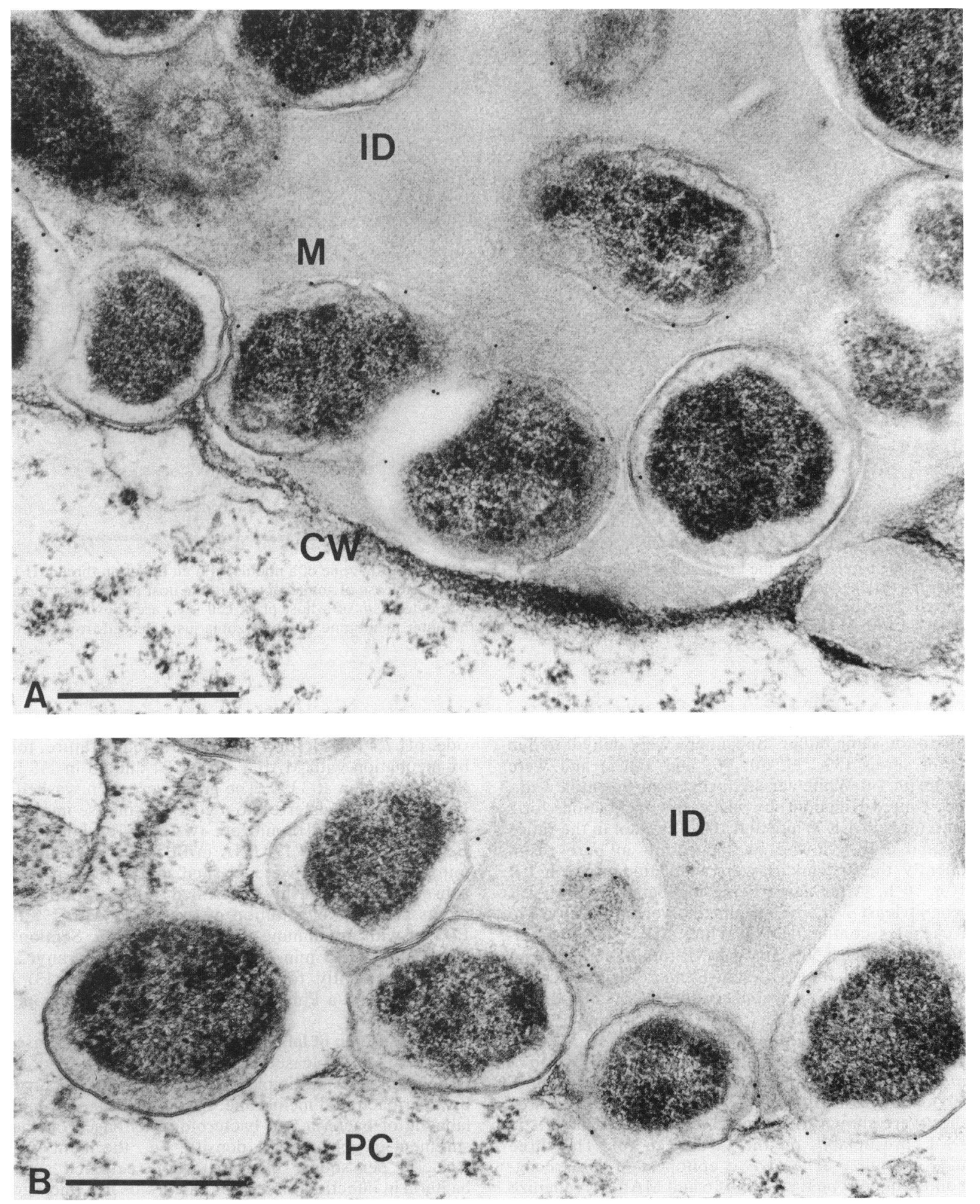

FIG. 2. Infection droplets in the invasion zone of a root nodule. (A) Normally shaped bacteria in an infection droplet (ID), containing matrix material (M) bordered by a very thin cell wall (CW). Immunolabeling with MAb 24 shows label on the outer membranes of the bacteria. Bar, $0.5 \mu \mathrm{m}$. (B) An infection droplet (ID) with bacteria at the moment of endocytosis in the host plant cell cytoplasm (PC). Immunolabeling with MAb 24 resulted in label on the outer membrane of the bacteria. Bar, $0.5 \mu \mathrm{m}$. 

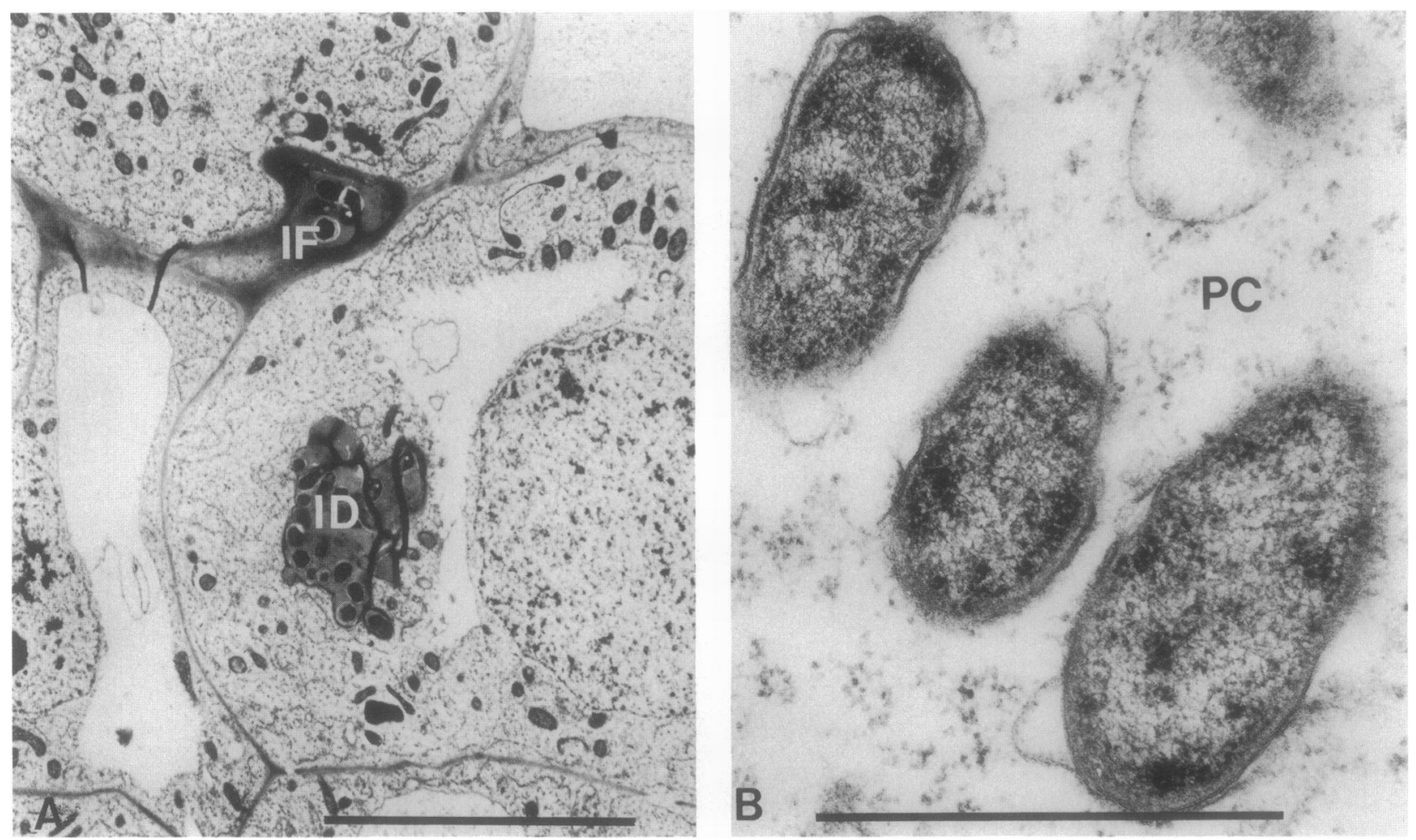

FIG. 3. Young bacteroids in the invasion zone of a nodule. (A) Cells in the invasion zone of a nodule with an infection thread (IF) and an infection droplet (ID). The plant cell organelles are dispersed in the cytoplasm. Release of some bacteria in the host plant cell cytoplasm has just occurred. Bar, $10 \mu \mathrm{m}$. (B) Detail of panel A. Young bacteroids in the cytoplasm of a host plant cell (PC) are shown. The section is immunolabeled with MAb 24. Only a few gold particles are present at the outer membrane of the rhizobia just released from the infection droplets. Bar, $1 \mu \mathrm{m}$.

buffer for $30 \mathrm{~min}$ and postfixed for $2 \mathrm{~h}$ in $1 \%$ osmium tetroxide in the same buffer. Specimens were dehydrated in an ethanol series $(30,50,70,96$, and 100\%) and were infiltrated with LR White acrylic resin (Agar Scientific Ltd., Stansted, United Kingdom) by successive incubations for 1 $\mathrm{h}$ with mixtures of LR White and $100 \%$ ethanol in the ratios $1: 2,1: 1$ and $2: 1$, followed by incubation in pure resin. Subsequently the specimens were incubated in fresh LR White for $16 \mathrm{~h}$. After again being incubated in fresh LR White for at least $2 \mathrm{~h}$, the specimens were transferred to gelatin capsules containing LR White. LR White was allowed to polymerize at $50^{\circ} \mathrm{C}$ for $16 \mathrm{~h}$. Ultrathin sections were cut with a Reichert-Jung Ultracut-E microtome equipped with a diamond knife. Silver-gold sections were collected on collodion-coated nickel grids.

MAbs. Three MAbs, MAb 3, MAb 16, and MAb 24, were obtained by immunizing mice with a cell envelope fraction of $R$. leguminosarum bv. viciae 248 , followed by the fusion of spleen lymphocytes with a myeloma cell line. All three antibodies were shown to recognize epitopes characteristic for LPS I, presumably on the $O$ antigen (6). The three antibodies recognize at least two epitopes; MAb 3 recognizes a different epitope than MAb 16 and MAb 24 recognize (7).

Immunogold localization. Immunolabeling was carried out on sections treated with aqueous sodium metaperiodate for 1 $h$ (in order to overcome the possible masking of antigen sites by osmium [9]) and on untreated sections. Ultrathin sections on grids were placed on drops of blocking buffer $(1 \%$ [wt/vol] bovine serum albumin [BSA; Sigma fraction V] in $10 \mathrm{mM}$ sodium hydrogen-dihydrogen phosphate- $0.8 \%$ sodium chloride, $\mathrm{pH} 7.4$ [PBS]) for $5 \mathrm{~min}$ at room temperature, followed by incubation with MAb 3, 16, or 24 diluted in $1 \%$ BSA in PBS for $30 \mathrm{~min}$ at $37^{\circ} \mathrm{C}$. The grids were then washed in $1 \%$ BSA in PBS, transferred to a goat anti-mouse immunoglobulin G 10-nm gold conjugate (GAM G10; Janssen, Olen, Belgium), diluted in $1 \%$ BSA in PBS, and incubated for 30 min at $37^{\circ} \mathrm{C}$. Grids were washed in $1 \% \mathrm{BSA}$ in PBS and subsequently in freshly bidistilled water. Control experiments included substitution of the MAbs with $1 \%$ BSA in PBS or with preimmune immunoglobulin G. Sections were poststained for $5 \mathrm{~min}$ in saturated aqueous uranyl acetate and subsequently for $5 \mathrm{~min}$ in lead citrate (13) before examination in a Philips EM300 electron microscope operating at $60 \mathrm{kV}$.

Quantification of labeling. The term bacteroid is used here for all rhizobia released from the infection thread, i.e., all rhizobia present in the plant cell cytoplasm and surrounded by a peribacteroid membrane. Quantification of specific gold labeling of bacteria and bacteroids was based on the measurement of gold particle density, i.e., the number of gold particles per square micrometer of sectioned surface of bacteria in infection threads or bacteroids in a micrograph of usually more than one rhizobium. Gold labeling of bacteria in infection droplets was not separately quantified because infection droplets were rather rare in the sections. For statistical analysis, measurements of a number of micrographs of bacteria or of bacteroids labeled with one of the three MAbs were used.

Bacterium and bacteroid labeling were compared by non- 

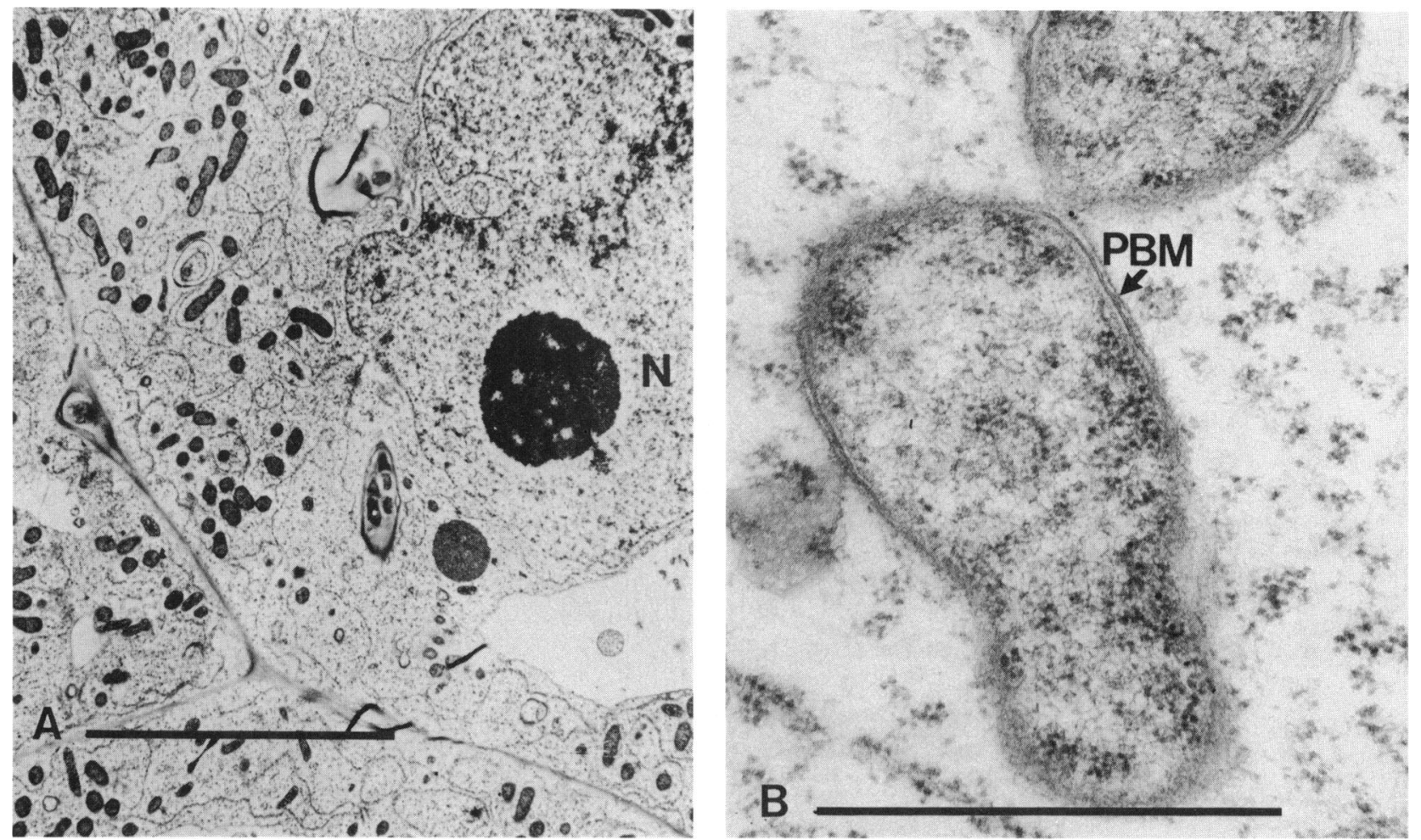

FIG. 4. Bacteroids in the early symbiotic zone of a nodule. (A) An infected cell of the early symbiotic zone of a nodule showing infection threads and an infection droplet close to the nucleus $(\mathrm{N})$. Some of the bacteroids are dividing. Mitochondria and plastids are not yet located adjacent to the plasma membrane as is the case in infected cells of the symbiotic zone. Bar, $10 \mu \mathrm{m}$. (B) Young bacteroids whose bacterial outer membrane is surrounded by a peribacteroid membrane (PBM). After immunolabeling with MAb 24, the outer membrane is not labeled. Bar, $1 \mu \mathrm{m}$.

parametric methods (15). To determine whether differences among the means were statistically significant, the KruskallWallis two-way analysis of variance was performed. Subsequent two-by-two comparison of samples was performed by the Mann-Whitney U test.

Differences in gold particle densities between bacteria and bacteroids could be attributable to differences in ratio between cross-section circumference and section surface due to possible size differences. In order to test this possibility, the ratio between circumference and surface for bacteria and bacteroids was estimated. The ratios for bacteria in infection threads and for both young and mature bacteroids appeared to be the same, however.

\section{RESULTS}

Bacteria in infection threads. Figure 1 shows rhizobia in obliquely and (in part) transversely sectioned infection threads in infected nodule cells. The bacteria were irregularly shaped and for the most part closely packed in the threads. The bacteria showed a rather electron-dense cytoplasm, and some of them contained poly- $\beta$-hydroxybutyrate deposits. Outer and cytoplasmic membranes were well fixed, i.e., plasmolysis had not occurred. The outer membrane was always more electron dense and more visible than the cytoplasmic membrane. Bacteria in infection droplets were shaped like free-living bacteria and contained less electrondense cytoplasm (Fig. 2). The infection thread matrix appeared as an amorphous substance, whereas the infection thread cell wall was fibrillar (Fig. 1). The thickness of the infection thread cell wall varied, and the wall was absent at the moment of endocytosis of the bacteria in the host plant cell cytoplasm (Fig. 2B). Electron-translucent areas were sometimes present around the bacteria (Fig. 1A and 2B).

Immunolabeling with each of the three MAbs resulted in the labeling of the outer membrane of the bacteria (Fig. 1 and 2). Very few gold particles appeared in the electron-translucent area surrounding the bacteria or in the infection thread matrix. Bacteria in the infection droplets seem to contain fewer gold particles at their outer membranes than bacteria in the older parts of infection threads. Control sections immunolabeled without MAb did not show gold particles.

Bacteroids. Figure $3 \mathrm{~A}$ shows an electron micrograph of some infected $V$. sativa nodule cells in the invasion zone (11). Infection threads and infection droplets were present, and only a few bacteria had been released from the droplets. Cell division and differentiation of released rhizobia had just started. Figure 4A shows an infected cell from the early symbiotic zone (11), with released rhizobia showing cell division. Figure 5A shows a cell in the symbiotic zone of the nodule (11), containing many fully developed bacteroids. Resemblances and differences in morphology of bacteroids from various nodule zones are clearly visible in Fig. 3B, 4B, and 5B. Outer and cytoplasmic membranes of the bacteroids were always closely aligned. Older bacteroids contained a more electron-dense cytoplasm (Fig. 5B) than young ones (Fig. 3B and 4B). The bacteroids were surrounded by the peribacteroid membrane which separated them from the plant cytoplasm (Fig. 3B, 4B, and 5B). The size of the 

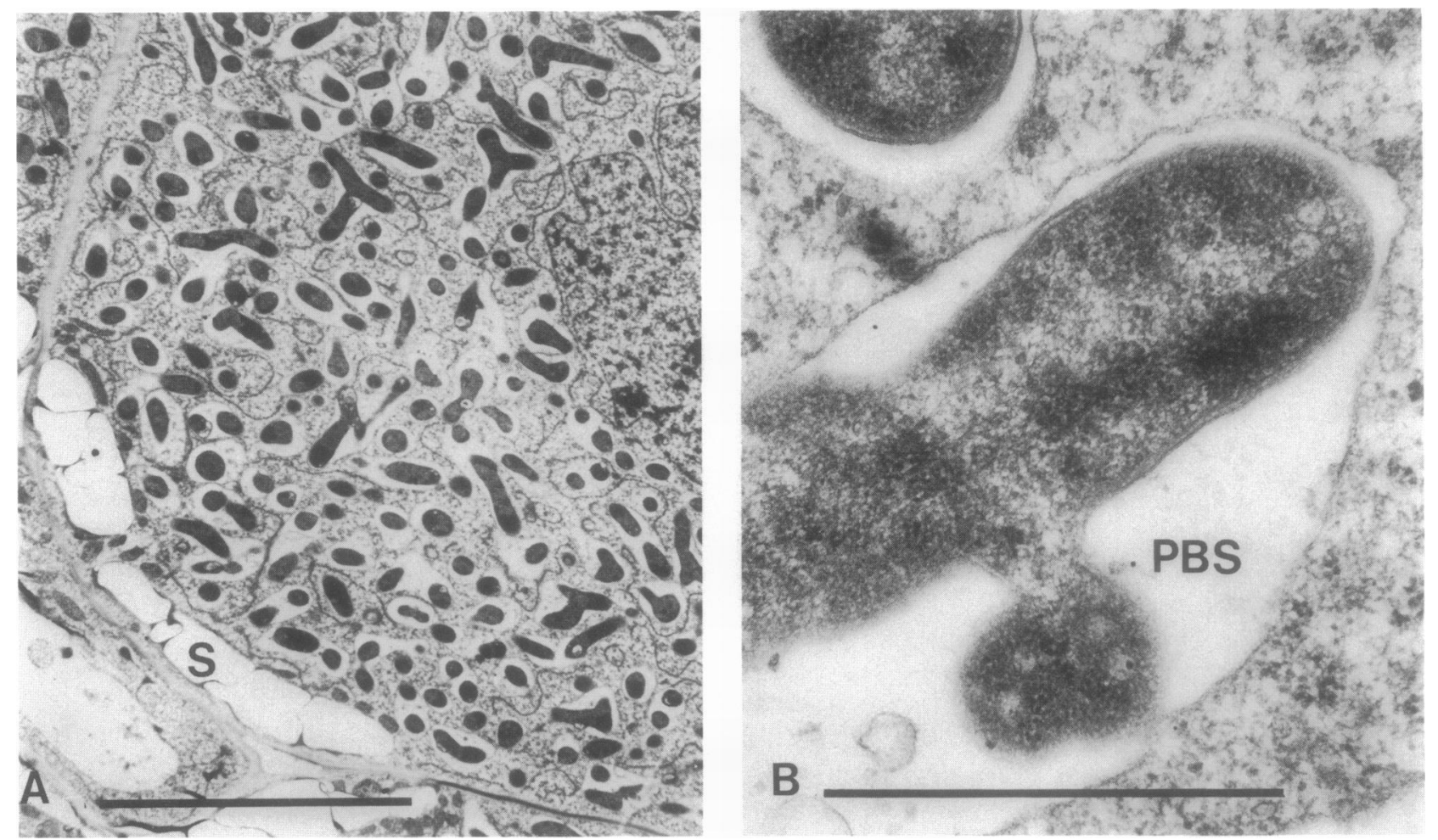

FIG. 5. Bacteroids in the symbiotic zone of a nodule. (A) An infected cell of the symbiotic zone of a nodule. Many mature bacteroids fill the host plant cell cytoplasm. Note the starch grains $(\mathrm{S})$ in plastids at the cell periphery. Bar, $10 \mu \mathrm{m}$. (B) Fully developed bacteroids with a rather electron-dense cytoplasm and a relatively large peribacteroid space (PBS), immunolabeled with MAb 3; outer membranes and peribacteroid membrane are not labeled. Bar, $1 \mu \mathrm{m}$.

peribacteroid space varied, but it was larger in the older bacteroids (Fig. 5B).

Immunolabeling with MAbs 3, 16, and 24 showed that the corresponding epitopes of LPS I were no longer present at the outer membrane of most bacteroids in either nodule zone (Fig. 3B, 4B, and 5B); i.e., from the moment of endocytosis, the rhizobia had lost almost all of the LPS I epitopes. Only a minority of bacteroids showed some gold particles at their outer membrane or in the peribacteroid space. Control sections without MAb did not show gold particles.

Quantification of labeling. Gold particle densities of bacteria in infection threads and of bacteroids after immunogold labeling with MAbs 3, 16, and 24 are shown in Fig. 6. Kruskall-Wallis two-way analysis of variance showed that the difference in labeling was statistically significant $(P<$ 0.0001 ). Subsequent two-by-two comparison by the MannWhitney $U$ test indicated that the gold particle density after labeling with MAb 3 was not significantly different from that with MAb 16 and significantly larger than with MAb $24(P<$ 0.01). After labeling with MAb 16, the gold particle density was significantly larger than it was with MAb $24(P<$ 0.0001 ). Gold particle densities for the bacteroids were very low compared with those for the bacteria for all three MAbs (Fig. 6) $(P<0.0001$ for all three MAbs). In the bacteroids, the gold particle density with MAb 16 was significantly larger than with MAb $3(P<0.01)$ and with MAb $24(P<0.001)$.

Ratios between the circumference and surface of cells in the thin sections were $5.1 \mu^{-1}$ for bacteria in the infection thread (measurements, $n=17$; cells, $n=61$ ) as well as for bacteroids (measurements, $n=19$; cells, $n=15$ ). This indicates that although bacteroids become larger, they change shape in such a way that the circumference-tosurface ratio is maintained.

Comparison between gold particle densities in sections treated with and without aqueous sodium metaperiodate (9)

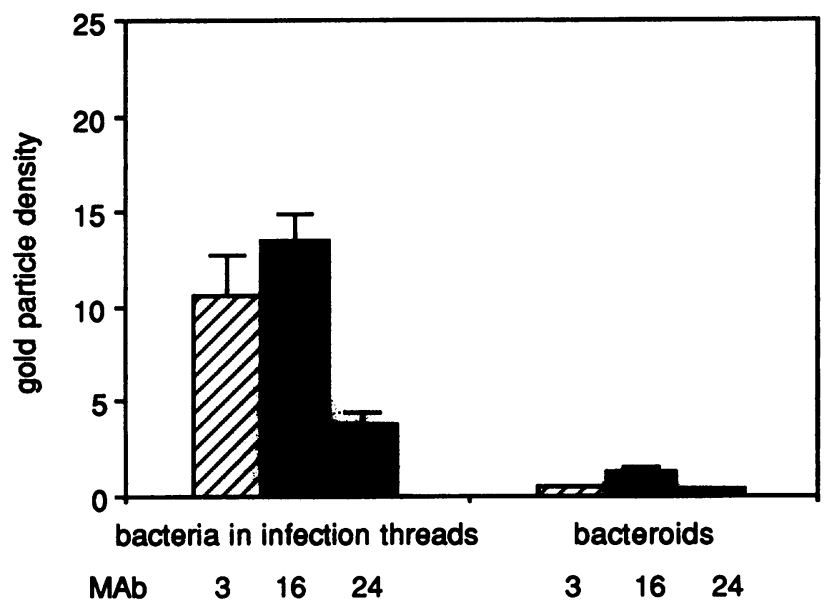

FIG. 6. Mean gold particle densities (particles per square micrometer of sectioned cell surface) and standard error for bacteria in infection threads and for bacteroids after immunolabeling. Numbers of measurements are 23,17 , and 13 for bacteria and 16,21 , and 12 for bacteroids labeled with MAbs 3, 16, and 24, respectively. The numbers of cells are 98,73 , and 37 for bacteria and 66,51 , and 46 for bacteroids. 
gave no indication of antigen masking by osmium tetroxide. Therefore, the data from treated and untreated sections were pooled.

\section{DISCUSSION}

Data of the present study are consistent with the immunochemical studies of de Maagd et al. (7) which showed a decreased amount of LPS I-specific epitopes in isolated cell envelopes of bacteroids from pea nodules with all three MAbs; the immunoreaction was clearly weaker than with cell envelopes of free-living bacteria. These immunochemical techniques, however, cannot distinguish between different stages of differentiation of rhizobia in the nodule. The use of the same MAbs in immunoelectron microscopy allowed us to follow the fate of these LPS I epitopes in more detail.

The LPS I-specific epitopes recognized by the MAbs were, as expected, localized almost exclusively on outer membranes of the bacteria. In infection threads, there was no difference in the amount of label between bacteria in the invasion zone, in the early symbiotic zone, and in the symbiotic zone of the nodule. After endocytosis of the bacteria in the host cells, the LPS I epitopes were detected only in very low quantities, if at all, with all three MAbs. In this regard, there was no difference between young and old bacteroids.

The present immunocytochemical findings suggest that the presence of the LPS I epitopes decreased rather abruptly at the onset of endocytosis. If this decrease were due only to a decrease in production, one would expect a more gradual decline in immunolabeling than was observed. Therefore, it seems more likely that the epitopes are actively degraded or modified. The disappearance of LPS I epitopes seems to start already in the infection droplets. This suggests that loss of LPS I epitopes relates to the droplet environment, a situation which supposedly resembles more closely the situation in a plant than do the circumstances in an infection thread surrounded by a plant cell wall.

The three LPS I epitopes were almost completely lacking after release of the bacteria from the infection droplets. Thus, no indications of removal and/or transfer of LPS I epitopes during the differentiation of the bacteroids were found. We also did not observe replacement of outer membranes in bacteroids by sloughing off membranes as described by Bal et al. and Bal and Wong for slow-growing rhizobia $(1,2)$. Furthermore, there were no indications of transfer of the LPS I epitopes to the peribacteroid space, to the peribacteroid membrane of the bacteroids, or to the host cell cytoplasm, as were found for other LPS epitopes (3).

It is notable that the LPS I epitopes in this study behave quite differently from the MAC 203 epitope reported by VandenBosch et al. (18). Striking points of difference are the dependence or lack of dependence on the nodule region and on the differentiation stage of rhizobia. The MAC 203 epitope is expressed in bacteria in infection threads as well as in young and mature bacteroids only in mature regions of the Pisum nodule. The LPS I epitopes, however, have disappeared in young and mature bacteroids in all regions of the Vicia nodule.

The present results show that the disappearance of LPS I epitopes probably starts in the infection droplet and occurs very rapidly. This suggests that biosynthesis of the LPS I epitopes recognized by MAbs 3, 16, and 24 stops around the moment of endocytosis and that the epitopes are actively degraded or modified.

\section{ACKNOWLEDGMENTS}

We thank I. H. M. Mulders and T. Tak for assistance in the growth of bacteria and plants, G. P. G. Hock for making Fig. 6, and J. W. Kijne for comments on the manuscript.

\section{REFERENCES}

1. Bal, A. K., S. Shantharam, and D. P. S. Verma. 1980. Changes in the outer cell wall of Rhizobium during development of root nodule symbiosis in soybean. Can. J. Microbiol. 26:1096-1103.

2. Bal, A. K., and P. P. Wong. 1982. Infection process and sloughing off of rhizobial outer membrane in effective nodules of lima bean. Can. J. Microbiol. 28:890-896.

3. Bradley, D.J., G. W. Butcher, G. Galfre, E. A. Wood, and N. J. Brewin. 1986. Physical association between the peribacteroid membrane and lipopolysaccharide from the bacteroid outer membrane in Rhizobium-infected pea root nodule cells. J. Cell Sci. 85:47-61.

4. Brewin, N. J., E. A. Wood, A. P. Larkins, G. Galfre, and G. W. Butcher. 1986. Analysis of lipopolysaccharide from root nodule bacteroids of Rhizobium leguminosarum using monoclonal antibodies. J. Gen. Microbiol. 132:1959-1968.

5. Carlson, R. W. 1984. Heterogeneity of Rhizobium lipopolysaccharides. J. Bacteriol. 158:1012-1017.

6. De Maagd, R. A., R. de Rijk, I. H. M. Mulders, and B. J. J. Lugtenberg. 1989. Immunological characterization of Rhizobium leguminosarum outer membrane antigens by use of polyclonal and monoclonal antibodies. J. Bacteriol. 171:1136-1142.

7. De Maagd, R. A., A. S. Rao, I. H. M. Mulders, L. Goosen-de Roo, M. C. M. van Loosdrecht, C. A. Wijffelman, and B. J. J. Lugtenberg. 1989. Isolation and characterization of mutants of Rhizobium leguminosarum bv. viciae 248 with altered lipopolysaccharides: possible role of surface charge or hydrophobicity in bacterial release from the infection thread. J. Bacteriol. 171:1143-1150.

8. De Maagd, R. A., C. van Rossum, and B. J. J. Lugtenberg. 1988. Recognition of individual strains of fast-growing rhizobia by using profiles of membrane proteins and lipopolysaccharides. J. Bacteriol. 170:3782-3785.

9. Doman, D. C., and R. N. Trelease. 1985. Protein A-gold immunocytochemistry of isocitrate lyase in cotton seeds. Protoplasma 124:157-167.

10. Long, S. R. 1989. Rhizobium-legume nodulation. Cell 56:203214.

11. Newcomb, W. 1981. Nodule morphogenesis and differentiation. Int. Rev. Cytol. Suppl. 13:247-298.

12. Priefer, U. B. 1989. Genes involved in lipopolysaccharide production and symbiosis are clustered on the chromosome of Rhizobium leguminosarum biovar viciae VF39. J. Bacteriol. 171:6161-6168.

13. Reynolds, E. S. 1963 . The use of lead citrate at high $\mathrm{pH}$ as an electron-opaque stain in electron microscopy. J. Cell Biol. 17:208-212.

14. Robertson, J. G., B. Wells, N. J. Brewin, E. A. Wood, C. D. Knight, and J. A. Downie. 1985. The legume-Rhizobium symbiosis: a cell surface interaction. J. Cell Sci. Suppl. 2:317-331.

15. Siegel, S. 1956. Nonparametric statistics for the behavioral sciences. McGraw-Hill Book Company, Inc., New York.

16. Van Brussel, A. A. N., K. Planqué, and A. Quispel. 1977. The wall of Rhizobium leguminosarum in bacteroid and free-living forms. J: Gen. Microbiol. 101:51-56.

17. Van Brussel, A. A. N., T. Tak, A. Wetselaar, E. Pees, and C. A. Wijffelman. 1982. Small Leguminosae as test plants for nodulation of Rhizobium leguminosarum and other rhizobia and $\mathrm{Ag}$ robacterium harbouring a leguminosarum Sym plasmid. Plant Sci. Lett. 27:317-325.

18. VandenBosch, K. A., N. J. Brewin, and E. L. Kannenberg. 1989. Developmental regulation of a Rhizobium cell surface antigen during growth of pea root nodules. J. Bacteriol. 171:4537-4542. 